\title{
NFkB-mediated CXCL1 production in spinal cord astrocytes contributes to the maintenance of bone cancer pain in mice
}

\author{
Jie Xu' ${ }^{1}$, Ming-Di Zhu' ${ }^{2}$ Xin Zhang ${ }^{1}$, Hao Tian ${ }^{3}$, Jin-Hua Zhang ${ }^{4}$, Xiao-Bo $W^{1}{ }^{1}$ and Yong-Jing Gao ${ }^{1 *}$
}

\begin{abstract}
Background: Bone cancer pain (BCP) is one of the most disabling factors in patients suffering from primary bone cancer or bone metastases. Recent studies show several chemokines (for example, CCL2, CXCL10) in the spinal cord are involved in the pathogenesis of BCP. Here we investigated whether and how spinal CXCL1 contributes to BCP.

Methods: Mouse prostate tumor cell line, RM-1 cells were intramedullary injected into the femur to induce BCP. The mRNA expression of CXCL1 and CXCR2 was detected by quantitative real-time PCR. The protein expression and distribution of CXCL1, NFKB, and CXCR2 was examined by immunofluorescence staining and western blot. The effect of CXCL1 neutralizing antibody, NFKB antagonist, and CXCR2 antagonist on pain hypersensitivity was checked by behavioral testing.

Results: Intramedullary injection of RM-1 cells into the femur induced cortical bone damage and persistent (>21 days) mechanical allodynia and heat hyperalgesia. Tumor cell inoculation also produced CXCL1 upregulation in activated astrocytes in the spinal cord for more than 21 days. Inhibition of CXCL1 by intrathecal administration of CXCL1 neutralizing antibody at 7 days after inoculation attenuated mechanical allodynia and heat hyperalgesia. In cultured astrocytes, TNF-a induced robust CXCL1 expression, which was dose-dependently decreased by NFKB inhibitor. Furthermore, inoculation induced persistent NFKB phosphorylation in spinal astrocytes. Intrathecal injection of NFKB inhibitor attenuated BCP and reduced CXCL1 increase in the spinal cord. Finally, CXCR2, the primary receptor of CXCL1, was upregulated in dorsal horn neurons after inoculation. Inhibition of CXCR2 by its selective antagonist SB225002 attenuated BCP.

Conclusion: NFKB mediates CXCL1 upregulation in spinal astrocytes in the BCP model. In addition, CXCL1 may be released from astrocytes and act on CXCR2 on neurons in the spinal cord and be involved in the maintenance of BCP. Inhibition of the CXCL1 signaling may provide a new therapy for BCP management.
\end{abstract}

Keywords: Bone cancer pain, Chemokines, CXCL1, CXCR2, NFkB, Astrocytes, Astroglia-neuron interaction

\section{Background}

Bone cancer pain $(\mathrm{BCP})$ is the most common symptom detected in patients with advanced breast, prostate, and lung cancer [1]. Current treatment strategies often provide inadequate analgesia and unacceptable side effects [2]. Understanding the underlying mechanisms related to the development of $\mathrm{BCP}$ is important for effectively treating these patients.

\footnotetext{
* Correspondence: gaoyongjing@hotmail.com

'Pain Research Laboratory, Institute of Nautical Medicine, Jiangsu Key Laboratory of Neuroregeneration, Nantong University, 19 Qixiu Road, Nantong 226001, China

Full list of author information is available at the end of the article
}

Glial cell-mediated neuroinflammation has been recently shown to play a pivotal role in the pathogenesis of chronic pain $[3,4]$. Tissue injury/inflammation, nerve injury, and tumor growth can induce glial cells (astrocytes and microglia) to be reactive and release a variety of inflammatory mediators, including proinflammatory cytokines and chemokines, which may augment the nociceptive signals in the spinal cord [5-8]. Chemokines are small secreted proteins and are key molecules involved in the migration and homeostasis of immune cells. Recent studies have shown that some chemokines in the spinal cord are involved in BCP. For example, CCL2 expression is increased in spinal 
astrocytes and microglia in mice with BCP [9]. Intrathecal administration of CCL2 neutralizing antibody attenuates tumoral hyperalgesia $[9,10]$. Tumor cell inoculation also induces the increases of CXCL10 and its major receptor CXCR3 in the spinal cord. Blocking the function of CXCL10/CXCR3 pathway via anti-CXCL10 antibody or CXCR3 antagonist prevents the development of $\mathrm{BCP}$ and microglial activation [11].

CXCL1 is a member of CXC family and is also known as keratinocyte-derived chemokines (KC) or growthrelated oncogene (GRO). CXCL1 is highly expressed in melanoma cell lines and promotes malignant melanoma tumor progression [12]. CXCL1 also modulates neuronal excitability of DRG neurons by increasing sodium currents, potassium currents, and the function of TRPV1 channels [13-15]. In the spinal cord, CXCL1 is upregulated in astrocytes after spinal nerve ligation and contribute to the maintenance of neuropathic pain [16]. However, little is known about whether CXCL1 participates in the maintenance of BCP.

Nuclear factor kappa B (NFkB) is a transcription factor which serves as a transducer between extracellular signals and gene expression. NFKB is involved in CXCL1 transcription in Hs294T malignant melanoma cells [17]. Moreover, emerging evidence indicates that the activation of NFKB following tissue injury or nerve damage is related to the generation of chronic pain [18-20]. Whether NFKB mediates CXCL1 expression in the spinal astrocytes and contributes to $\mathrm{BCP}$ needs to be investigated.

In this study, we examined CXCL1 expression and distribution in the spinal cord after inoculation of mouse prostate cell line, RM-1 cells into the femur. We also evaluated the role of $\mathrm{NFKB}$ in CXCL1 production and pain hypersensitivity after tumor cell inoculation. As the biological effects of chemokines are mediated via interaction with its $\mathrm{G}$ protein-coupled receptor, and CXCR2 is the primary receptor of CXCL1, we further investigated the expression and distribution of CXCR2 in the spinal cord and the antinociceptive effect of CXCR2 antagonist.

\section{Methods}

\section{Animals and tumor inoculation}

Experiments were performed on adult (8 weeks) male C57Bl/6 mice. All mice had free access to food and water with a 12/12 light/dark cycle. All animal procedures in this study were performed according to the guidelines of the International Association for the Study of Pain and approved by the Animal Care and Use Committee of Nantong University. Mice prostate tumor cell line, RM-1, was purchased from the Cell Bank of Type Culture Collection of Chinese Academy of Sciences (Shanghai, China). RM-1 cells were grown in Dulbecco's modified Eagle medium (DMEM) containing 4,500 mg/L glucose, $100 \mathrm{mg} / \mathrm{L}$ penicillin, $100 \mathrm{mg} / \mathrm{L}$ streptomycin, and supplemented with $10 \%$ fetal bovine serum (FBS) at $37^{\circ} \mathrm{C}$. The RM-1 cells were collected following enzymatic digestion, centrifuged, and resuspended in phosphate buffered saline (PBS) in a concentration of $5 \times 10^{7}$ cells $/ \mathrm{mL}$. The animals were anesthetized with sodium pentobarbital (50 mg/kg, i.p.). An arthrotomy was done to expose the condyles of the distal femur. PBS containing $10^{6} \mathrm{RM}-1$ cells $(20 \mu \mathrm{L})$ was injected into the intramedullary space of the right femur with a $30 \mathrm{G}$ needle and the injection site was sealed with bone wax. Sham control mice were injected with same amount of heat-inactivated RM-1 cells.

\section{Radiology}

To confirm cancer development in the femur, mice were radiographed at 21 days following implantation. The animals were anesthetized with sodium pentobarbital, placed in a prone position, and exposed to X-ray. The images were collected by Digital Diagnost Dual Detector (Philips).

\section{Drugs and administration}

The CXCL1 neutralizing antibody was purchased from Boster (Wuhan, China). SB225002, a potent and selective antagonist of CXCR2, was purchased from Tocris (Bristol, UK). BAY11-7082, a NFkB inhibitor, was purchased from Merck (Merck KGaA, Darmstadt, Germany). Intrathecal injection was made with a $30 \mathrm{G}$ needle between the L5 and L6 intervertebral space to deliver the reagents to the cerebral spinal fluid [21].

\section{Behavioral analysis}

Animals were habituated to the testing environment daily for at least 2 days before baseline testing. The room temperature remained stable for all experiments. For testing mechanical sensitivity, animals were put in boxes on an elevated metal mesh floor and allowed $30 \mathrm{~min}$ for habituation before examination. The plantar surface of each hindpaw was stimulated with a series of von Frey hairs with logarithmically incrementing stiffness (0.022.56 g, Stoelting, Wood Dale, IL, USA), presented perpendicular to the plantar surface (2 to $3 \mathrm{~s}$ for each hair). The 50\% paw withdrawal threshold was determined using Dixon's up-down method [22]. For testing heat sensitivity, animals were put in plastic boxes and allowed $30 \mathrm{~min}$ for habituation. Heat sensitivity was tested by radiant heat using Hargreaves apparatus (IITC Life Science Inc., Woodland Hills, CA, USA) and expressed as paw withdrawal latency (PWL). The radiant heat intensity was adjusted so that basal PWL is between 10 and $14 \mathrm{~s}$, with a cutoff of $18 \mathrm{~s}$ to prevent tissue damage.

\section{Primary astrocytes cultures}

Primary astrocytes cultures were prepared from cerebral cortexes of neonatal mice (P2) [23]. The cerebral hemi- 
spheres were isolated and transferred to ice-cold Hank's buffer and the meninges were carefully removed. Tissues were then minced into approximately $1 \mathrm{~mm}$ pieces, triturated, filtered through a $100 \mu \mathrm{m}$ nylon screen, and collected by centrifugation at 3,000 g for $5 \mathrm{~min}$. The cell pellets were dispersed with a pipette and resuspended in a medium containing 10\% FBS in low glucose DMEM. After trituration, the cells were filtered through a $40 \mu \mathrm{m}$ screen and then plated into 6-well plates at a density of $2.5 \times 10^{5}$ cells $/ \mathrm{cm}^{2}$, and cultured for about 10 days. The medium was replaced twice a week with 10\% FBS. Dibutyryl cAMP (0.15 mM, Sigma-Aldrich) was added to induce differentiation when the cells were grown to 95\% confluence. Prior to stimulation with LPS, OPTI-MEM was replaced. Astrocytes were incubated with TNF- $\alpha$ for different time periods. The treatment of the BAY11-7082 $(1,5,10 \mu \mathrm{M})$ was started $30 \mathrm{~min}$ prior to TNF- $\alpha$ treatment. After the treatment, the astrocytes were collected for ELISA or real-time PCR. To check the expression of CXCL1, some cells were cultured onto cover glasses at a density of $2.5 \times 10^{4}$ cells/ $\mathrm{cm}^{2}$, and fixed by $4 \%$ paraformaldehyde for $20 \mathrm{~min}$. Fluorescence double staining of CXCL1 and GFAP were performed (see below).

\section{Immunohistochemistry and immunocytochemistry}

After appropriate survival times, animals were deeply anesthetized with isoflurane and perfused through the ascending aorta with PBS followed by $4 \%$ paraformaldehyde with $1.5 \%$ picric acid in $0.16 \mathrm{M} \mathrm{PB}$. After the perfusion, the L4L5 spinal cord segments were removed and postfixed in the same fixative overnight. Spinal cord sections $(30 \mu \mathrm{m}$, freefloating) were cut in a cryostat and processed for immunofluorescence as we described previously [23]. The sections were first blocked with $2 \%$ goat serum for $1 \mathrm{~h}$ at room temperature. The sections were then incubated overnight at $4^{\circ} \mathrm{C}$ with the following primary antibodies: CXCL1 antibody (rabbit, 1:100; Boster), CXCR2 antibody (rabbit, 1:100; Boster), phospho-NF-кB p65 (Ser536) (рNFkB) antibody (mouse, 1:500; Sigma), GFAP antibody (mouse, 1:6,000; Millipore, Billerica, MA, USA), CD11b antibody (Mouse, 1:100, Serotec, Kidlington, UK), NeuN antibody (mouse, 1:3,000, Millipore). The sections were then incubated for $1 \mathrm{~h}$ at room temperature with Cy3- or FITC-conjugated secondary antibodies (1:1,000, Jackson ImmunoResearch). For double immunofluorescence, sections were incubated with a mixture of mouse and rabbit primary antibodies followed by a mixture of Cy3- and FITC-conjugated secondary antibodies. The stained sections were examined with a Leica fluorescence microscope, and images were captured with a CCD Spot camera. The specificity of CXCL1 and CXCR2 primary antibodies was tested by preabsorption experiment (Zhang et al. [16]).

For immunocytochemistry, cultured astrocytes were fixed with $4 \%$ paraformaldehyde for $20 \mathrm{~min}$ and processed for immunofluorescence with CXCL1 (rabbit, 1:100, Boster) and GFAP (mouse, 1:5,000; Millipore) antibody as shown above.

\section{Real-time PCR}

Total RNA was extracted from L4-5 spinal cord with the Trizol reagent (Invitrogen, Carlsbad, CA, USA). One microgram of total RNA was converted into cDNA using PrimeScript RT reagent kit (Takara, Shiga, Japan). The cDNA was amplified using the following primers: CXCL1 forward, 5'-GCT TGA AGG TGT TGC CCT CAG -3'; CXCL1 reverse, 5'-AGA AGC CAG CGT TCA CCA GAC-3'; CXCR2 forward, 5'-TCT GCT CAC AAA CAG CGT CGT A-3'; CXCR2 reverse, 5'-GAG TGG CAT GGG ACA GCA TC-3'; GAPDH forward, 5'-AAA TGG TGA AGG TCG GTG TGA AC-3'; GAPDH reverse, 5'-CAA CAA TCT CCA CTT TGC CAC TG-3'. The SYBR Premix Ex Taq ${ }^{\text {Tn }}$ II kit (Takara) was used for all PCR reactions, which were run on a Rotor-Gene 6000 RT-PCR machine (Hamburg, Germany). The PCR amplifications were performed at $95^{\circ} \mathrm{C}$ for $30 \mathrm{~s}$, followed by 45 cycles at $95^{\circ} \mathrm{C}$ for $5 \mathrm{~s}, 56^{\circ} \mathrm{C}$ for $30 \mathrm{~s}$, and $72^{\circ} \mathrm{C}$ for $30 \mathrm{~s}$. The melting curves were performed to validate the utility and specificity of each PCR product. The data were analyzed using Rotor-Gene 6000 series software, and evaluated using the Comparative CT Method $\left(2^{-\Delta \Delta C T}\right)$.

\section{ELISA}

Mouse CXCL1 ELISA kit was purchased from R\&D. Cultured cells were collected after treatment and homogenized in a lysis buffer containing protease and phosphatase inhibitors (Sigma). Protein concentrations were determined by BCA Protein Assay (Pierce, Rockford, IL, USA). For each reaction in a 96-well plate, $100 \mu \mathrm{g}$ of proteins were used, and ELISA was performed according to manufacturer's protocol. The standard curve was included in each experiment.

\section{Western blot}

Protein samples were prepared in the same way as for ELISA analysis, and $30 \mu \mathrm{g}$ of proteins were loaded for each lane and separated on SDS-PAGE gel (10\%). After the transfer, the blots were incubated overnight at $4^{\circ} \mathrm{C}$ with polyclonal antibodies against CXCR2 (1:100, rabbit, Boster) or pNFkB (1:1,000, rabbit, Cell Signaling Technology). For loading control, the blots were probed with GAPDH antibody (1:20,000, mouse, Sigma). These blots were further incubated with HRP-conjugated secondary antibody, developed in ECL solution, and exposed onto film (Millipore) for 1 to $5 \mathrm{~min}$. Specific bands were evaluated by apparent molecular size. The intensity of the selected bands was analyzed using Image $J$ software (NIH, Bethesda, MD, USA). 


\section{Quantification and statistics}

The behavioral and real-time PCR data were analyzed by one-way analysis of variance (ANOVA) followed by Newman-Keuls post hoc test. For western blot, the density of specific bands was measured with Image J. CXCR2 and $\mathrm{p}-\mathrm{NF} \kappa \mathrm{B}$ levels were normalized to loading control (GAPDH) [24]. For the analysis of CXCL1- or GFAPimmunoreactivity, four to five sections from the L4-L5 spinal cord segments were randomly selected. An image in a square on the medial two-thirds of the superficial dorsal horn (laminae I-III) was captured under $\times 20$ objective [25]. A numerical value of the immunofluorescence intensity was calculated with Image J (NIH). The intensity of the background was subtracted in each section and the CXCL1 or GFAP intensity was expressed as fold increase compared to control [24]. All data were expressed as mean \pm SEM. Differences between two groups were compared using Student's t-test. The criterion for statistical significance was $P<0.05$.

\section{Results}

Intramedullary inoculation of RM-1 cells produces the destruction of cortical bone and bone cancer pain

After RM-1 prostate tumor cells were inoculated into the intramedullary space of mouse femur, the overall conditions of mice were good and the body weight was gradually increased in 3 weeks (Figure 1A). By day 21 after inoculation, the loss of medullary bone and destruction of cortical bone were clearly observed in the distal one-third of the right femur (Figure 1B). No radiological change was found in the contralateral femur (Figure 1B) or control animals treated with heatinactivated tumor cells.

Pain behavioral studies showed that tumor cell inoculation produced an obvious pain hypersensitivity, which was characterized by heat hyperalgesia (increased response to a noxious heat stimulus) and mechanical allodynia (painful response to a normally innocuous mechanical stimulus) in the right hindpaws of inoculated mice. For heat sensitivity, the paw withdrawal latency (PWL) of inoculated mice to heat stimulation was decreased from $12.8 \pm 0.4 \mathrm{~s}$ before inoculation to $7.2 \pm 0.5 \mathrm{~s}$ on day $7(P<0.001)$, and maintained on day $10(7.4 \pm 0.4 \mathrm{~s}$, $P<0.001)$, day $14(6.7 \pm 1.1 \mathrm{~s}, P<0.01)$, and day $21(7.2 \pm$ $0.6 \mathrm{~s}, P<0.001$ ) (Figure $1 \mathrm{C}$ ), indicating the development of heat hyperalgesia. For mechanical sensitivity, the paw withdrawal threshold (PWT) of the ipsilateral paw, in response to von Frey hair stimulation, was decreased from $1.9 \pm 0.16 \mathrm{~g}$ before inoculation to $0.9 \pm 0.09 \mathrm{~g}$ on day $7(P<0.001), 0.3 \pm 0.10 \mathrm{~g}$ on day $10(P<0.001)$, $0.12 \pm 0.05 \mathrm{~g}$ on day $14(P<0.01)$, and $0.15 \pm 0.05 \mathrm{~g}$ on day $21(P<0.001$, Figure $1 \mathrm{D})$, indicating the progressive development of mechanical allodynia. The contralateral paw of inoculated mice or bilateral paws of shamtreated mice did not show changes in pain sensitivity (Figure 1C,D).
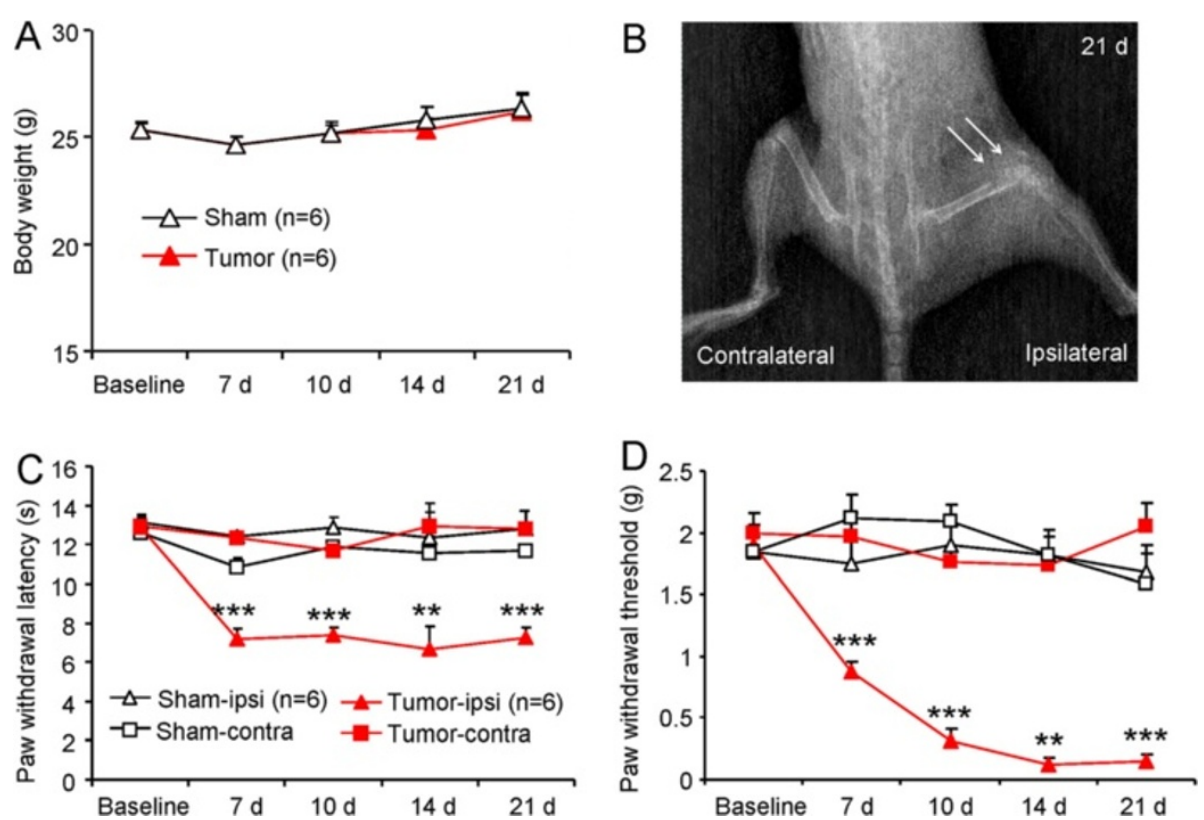

Figure 1 RM-1 cell inoculation induces BCP. (A) The animals' body weight was increased in 21 days in both sham-control and tumor-inoculated animals. (B) Radiography shows cortical bone damage in the distal one-third of the right femur (arrows) at 21 days after inoculation. (C, D) Behavioral tests show that mice displayed both heat hyperalgesia and mechanical allodynia in the ipsilateral paw after RM-1 cell inoculation. The PWL decreased at 7 days and maintained for more than 21 days (C). The PWT progressively decreased from 7 days to 14 days and maintained at 21 days (D). ${ }^{*} P<0.01,{ }^{* *} P<0.001$ vs. sham-ipsi. One-way ANOVA followed by Newman-Keuls test. $n=6$ mice per group. 
CXCL1 is persistently increased in spinal cord astrocytes after RM-1 cell inoculation

To examine CXCL1 expression in the spinal cord, we first performed quantitative real-time PCR. As shown in Figure 2A, CXCL1 mRNA expression was not changed in sham animals, but significantly increased at 7 days $(P<0.05), 14$ days $(P<0.05)$, and 21 days $(P<0.05)$ in inoculated animals. We then checked CXCL1 protein expression by immunostaining. Tumor cell inoculation induced a marked increase of CXCL1 expression in the ipsilateral spinal cord at 7 days, 14 days, and 21 days (Figure 2B-D). The statistical analysis of CXCL1-immunoreactive (IR) intensity showed a gradual increase from 7 days to 21 days after tumor cell inoculation $(P<0.001$, Figure $2 B)$.

To define the cellular distribution of CXCL1, we performed double staining of CXCL1 with different cell markers. The results showed that CXCL1-IR was colocalized with the astrocytic marker GFAP (Figure 2G), but not with microglial marker CD11b (Figure $2 \mathrm{H}$ ) or neuronal marker NeuN (Figure 2I), indicating the expression of CXCL1 by astrocytes.
Inhibition of CXCL1 by neutralizing antibody attenuates RM-1 cell inoculation-induced pain hypersensitivity

To investigate the role of endogenous CXCL1 in BCP, we intrathecally injected a CXCL1 neutralizing antibody at 7 days after inoculation and checked pain behaviors. CXCL1 neutralizing antibody at the dose of $4 \mu \mathrm{g}$ partly attenuated mechanical allodynia at $1 \mathrm{~h}(P<0.001), 3 \mathrm{~h}$ $(P<0.01)$, and $6 \mathrm{~h}(P<0.05)$. High dose $(8 \mu \mathrm{g})$ of CXCL1 neutralizing antibody almost reversed mechanical allodynia for $6 \mathrm{~h}$ (Figure 3A). Meanwhile, CXCL1 neutralizing antibody at doses of $4 \mu \mathrm{g}$ and $8 \mu \mathrm{g}$ attenuated heat hyperalgesia at $1 \mathrm{~h}, 3 \mathrm{~h}$ and $6 \mathrm{~h}(P<0.001$, Figure $3 \mathrm{~B})$. These data suggest CXCL1 is involved in tumor cell inoculation-induced pain hypersensitivity.

\section{Astrocytes activation in the spinal cord after RM-1 cell inoculation}

Because tumor cell inoculation induced CXCL1 increase in spinal astrocytes, we then examined astrocytes activation by checking GFAP expression in the spinal cord. In naïve animals, GFAP-positive astrocytes appeared to be in a resting state (Figure 4A). At 7 days after tumor cell
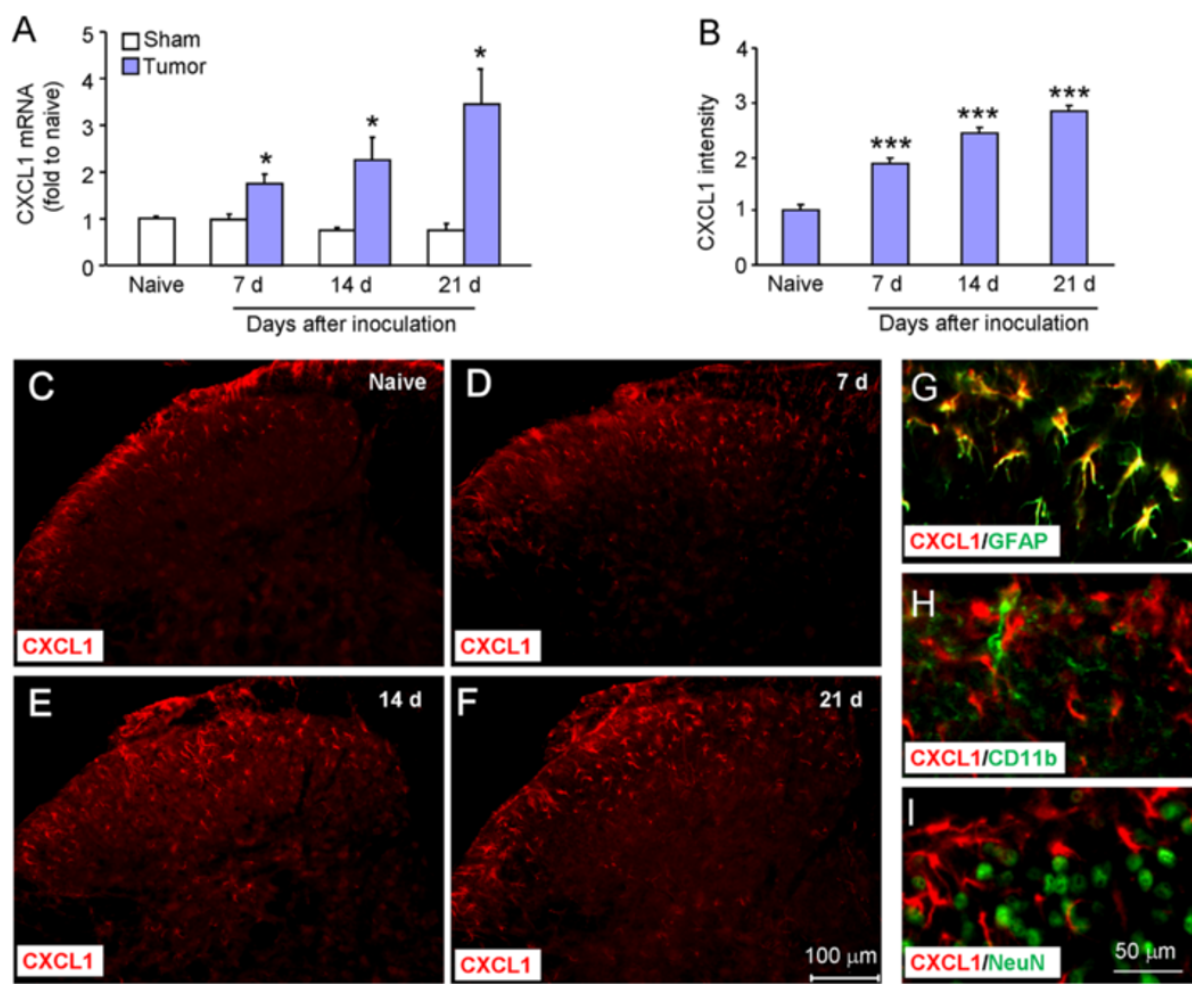

Figure 2 RM-1 cell inoculation induces CXCL1 upregulation in spinal astrocytes. (A) Real-time PCR results show the increase of CXCL1 mRNA expression in the spinal cord after inoculation. CXCL1 mRNA upregulation was gradually increased from 7 days to 21 days. ${ }^{*} P<0.05$ vs. sham control. $\mathrm{n}=4$ mice per group. (B-F) Immunostaining shows the CXCL1-IR was increased in the spinal cord at 7 days (D), 14 days (E), and 21 days $\mathbf{( F )}$. ${ }^{* *} P<0.001$ vs. naive. $n=4$ mice per group. (G-I) Double staining shows CXCL1 was colocalized with astrocytic marker, GFAP (G), but not with microglial marker CD11b (H) or neuronal marker NeuN (I) 


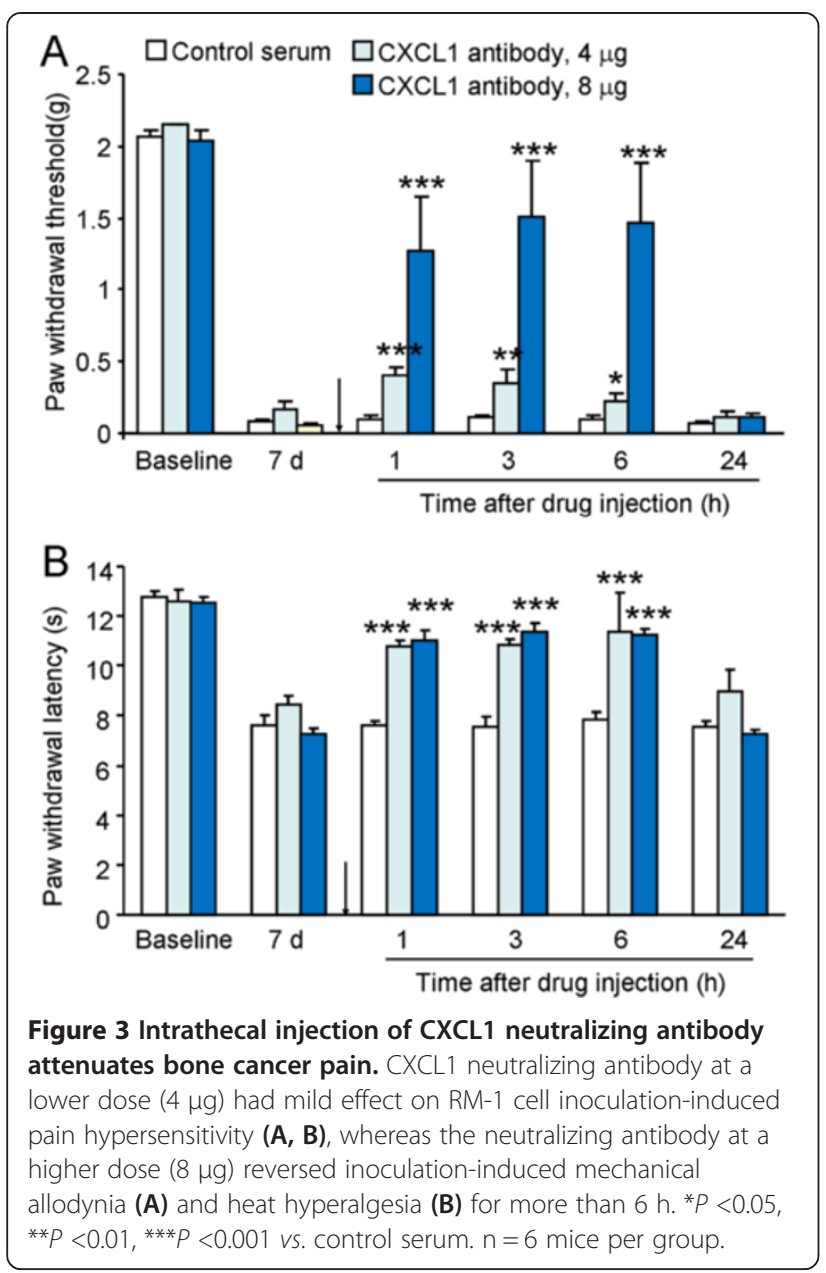

inoculation, the astrocyte profiles appeared larger and had more processes compared to naïve (Figure 4A,B). Intense astrocytic responses were discernible on day 14 (Figure 4C) and day 21 (Figure 4D). The statistical analysis of GFAP-IR intensity showed a gradual increase of GFAP expression in 21 days after tumor cell inoculation. GFAP expression was not increased in sham animals (Figure 4E).

\section{TNF- $\alpha$ induces CXCL1 upregulation via activation of NFKB} in cultured astrocytes

$\mathrm{NFKB}$ is a transcriptional factor and has been demonstrated to regulate the transcription of many inflammatory mediators, including those for chemokines and proinflammatory cytokines $[20,26]$. To check if NFkB is involved in CXCL1 production in astrocytes, we first prepared primary astrocyte cultures from cerebral cortexes of neonatal mice (P2) and stimulated with TNF- $\alpha$. As shown in Figure 5A, TNF- $\alpha$ incubation for $1 \mathrm{~h}$ increased CXCL1-IR (Figure 5A,B). Double staining with GFAP showed that majority of CXCL1-IR was colocalized with astrocytes (Figure 5C,D). We then examined the effects of NFKB inhibitor, BAY11-7082 on CXCL1 expression by ELISA and RT-PCR. Pretreatment of BAY11-7082, 30 min before TNF- $\alpha$ treatment, decreased CXCL1 protein expression by $24.4 \%$ and $40.9 \%$ at the doses of $1 \mu \mathrm{M}$ and $10 \mu \mathrm{M}$, respectively (Figure 5E). In addition, BAY11-7082 decreased CXCL1 mRNA expression by $50.0 \%, 60.7 \%$, and $74.2 \%$ at the doses of $1 \mu \mathrm{M}$, $5 \mu \mathrm{M}$, and $10 \mu \mathrm{M}$, respectively (Figure $5 \mathrm{~F}$ ). These data suggest $\mathrm{NF}_{\mathrm{K} B}$ is critical for mediating TNF- $\alpha$-induced CXCL1 production in cultured astrocytes.

\section{NFKB activation in spinal astrocytes after RM-1} cell inoculation

To check whether NFkB-CXCL1 pathway would be involved in tumor cell inoculation-induced CXCL1 upregulation and pain hypersensitivity, we first checked NFKB activation in the spinal cord after tumor cell inoculation. Western blot showed phosphorylated NFkB ( $\left.\mathrm{pNF}_{\mathrm{K}} \mathrm{B}\right)$ expression was gradually increased from 7 days to 21 days (Figure 6A,B). Immunostaining further showed a low expression of $\mathrm{pNF} \times \mathrm{B}$ in sham-treated mice (Figure $6 \mathrm{C}$ ) and an increased expression in inoculated mice (Figure 6D). Double staining showed $\mathrm{pNF}$ B $\mathrm{B}$ was predominantly colocalized with GFAP (Figure 6E-G).

\section{Inhibition of NFKB attenuated bone cancer pain and decreased CXCL1 upregulation in the spinal cord}

We then check the role of NFKB in the maintenance of BCP. We intrathecally injected BAY11-7082 (0.4 $\mu \mathrm{g}$ and $4 \mu \mathrm{g})$ at 7 days after inoculation. BAY11-7082 at the dose of $0.4 \mu \mathrm{g}$ had no effect on mechanical allodynia, but $4 \mu \mathrm{g}$ of this compound significantly attenuated mechanical allodynia at $1 \mathrm{~h}(P<0.01)$ and $3 \mathrm{~h}(P<0.05$, Figure 7A). The high dose of BAY11-7082 also attenuated heat hyperalgesia at $1 \mathrm{~h}(P<0.01)$ and $3 \mathrm{~h}$ $(P<0.001$, Figure 7B). BAY11-7082 also significantly decreased CXCL1-IR in the spinal cord $(P<0.001$, Figure $7 \mathrm{C}-\mathrm{E}$ ). These data suggest that $\mathrm{NF}_{\kappa} \mathrm{B}$ is involved in the tumor cell inoculation-induced CXCL1 upregulation in spinal astrocytes and pain hypersensitivity.

CXCR2 is persistently upregulated in spinal neurons and involved in bone cancer pain

CXCR2 is the major receptor of CXCL1. We further investigated CXCR2 expression and distribution in the spinal cord after tumor cell inoculation. RT-PCR showed CXCR2 mRNA was increased at 7 days and maintained for more than 21 days $(P<0.05$, Figure 8A). Western blot showed CXCR2 expression was gradually increased from 7 days to 21 days (Figure 8B). Immunostaining further showed a low expression of CXCR2 in naïve mice (Figure $8 \mathrm{C}$ ) and an increased expression in inoculated mice (Figure 8D). Double staining showed that majority CXCR2-IR was colocalized with $\mathrm{NeuN}$, indicating the 

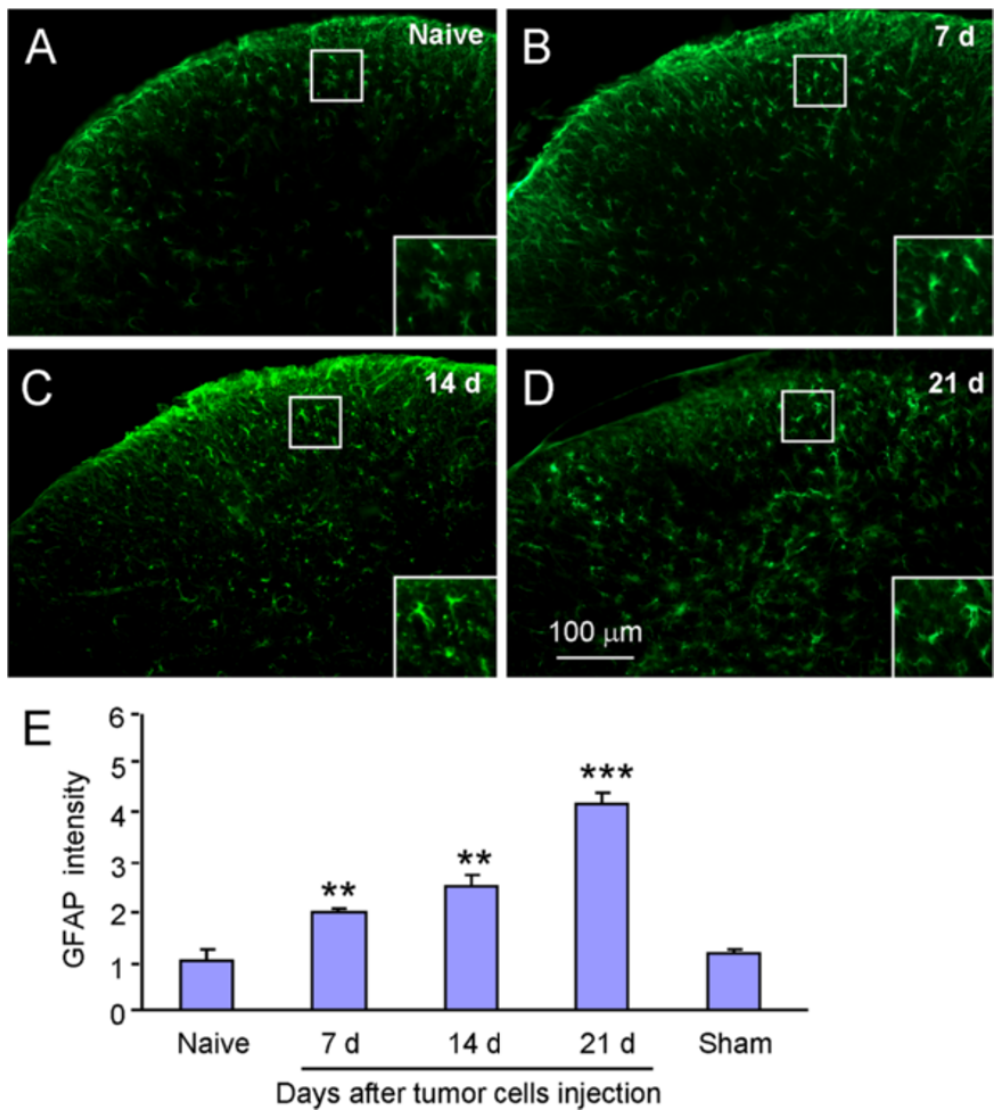

Figure 4 RM-1 cell inoculation induces GFAP upregulation in the spinal cord. (A-D) GFAP-IR was mild in naive mice (A), but increased at 7 days (B), 14 days (C), and 21 days (D) in inoculated mice. (E) Statistical analysis shows increased GFAP intensity after RM-1 cell inoculation. ${ }^{* *} \mathrm{P}<0.01,{ }^{* * *} \mathrm{P}<0.001$ vs. sham. $\mathrm{n}=4$ mice per group.

predominant production of CXCR2 by spinal neurons (Figure 8E-G).

To investigate the role of CXCR2 in the BCP, a selective and potent CXCR2 antagonist, SB225002 (5 $\mu \mathrm{g}$ and $20 \mu \mathrm{g}$ ) was intrathecally injected at 7 days after tumor cell inoculation. SB225002 at the dose of $5 \mu \mathrm{g}$ had no effect on mechanical allodynia or heat hyperalgesia, but SB225002 at the dose of $20 \mu \mathrm{g}$ significantly attenuated mechanical allodynia and heat hyperalgesia at $1 \mathrm{~h}$ and $3 \mathrm{~h}$ (Figure 8H,I), suggesting the involvement of CXCR2 in BCP.

\section{Discussion}

To investigate the mechanisms involved in the pathogenesis of BCP, animal models have been developed by injecting tumor cells lines (for example, osterolytic 2472 sarcoma, B16 melanoma, Walker 256 mammary gland carcinoma) into bones (for example, femur or tibia) [27]. Studies have shown that different cell line has unique phenotype in the extent of bone destruction, the type and severity of pain behaviors $[27,28]$. Here, we, for the first time injected mouse prostate cell line, RM-1 cells into mice femur. This cell line induced obvious cortical bone destruction of the femur and severe and persistent mechanical allodynia and heat hyperalgesia, suggesting it is suitable for BCP model. Using this model, our study demonstrated first that CXCL1 was dramatically increased in activated astrocytes in the spinal cord after tumor cell inoculation. Inhibition of CXCL1 attenuated inoculation-induced pain hypersensitivity. Second, $\mathrm{NF}-\mathrm{kB}$ was involved in CXCL1 production in cultured astrocytes and was activated in spinal astrocytes after inoculation. Inhibition of NFKB not only alleviated BCP but also decreased CXCL1 upregulation in the spinal cord. Third, CXCR2, the major receptor of CXCL1 was increased in spinal cord neurons. Intrathecal injection of CXCR2 antagonist attenuated $\mathrm{BCP}$. These data suggest that NFKB/CXCL1 and CXCR2 play an important role in the maintenance of $\mathrm{BCP}$ via astroglial-neuronal interaction in the spinal cord.

CXCL1 upregulation in activated astrocytes in the spinal cord and the involvement in bone cancer pain Recent studies have shown that CXCL1 expression in the spinal cord is changed in different pain models. 


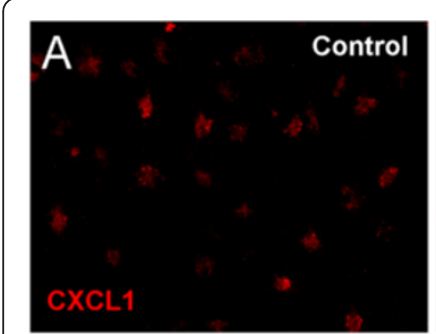

E

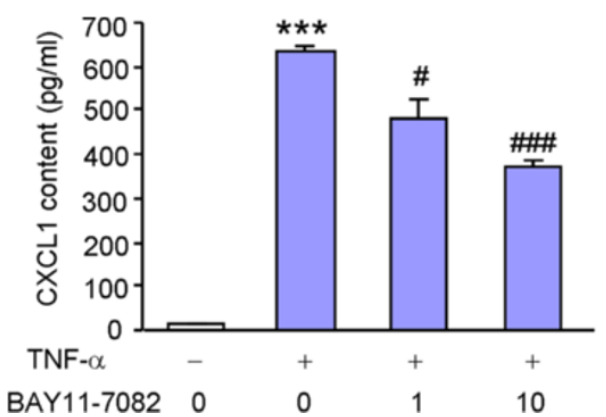

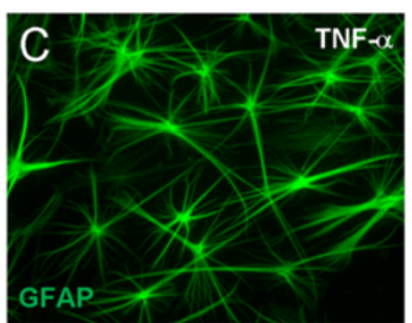

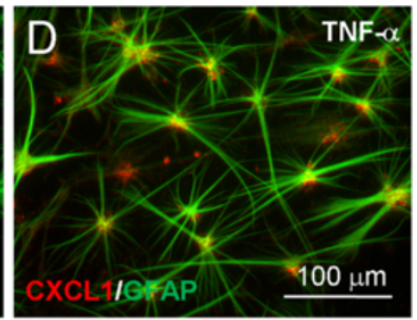

$\mathrm{F}$

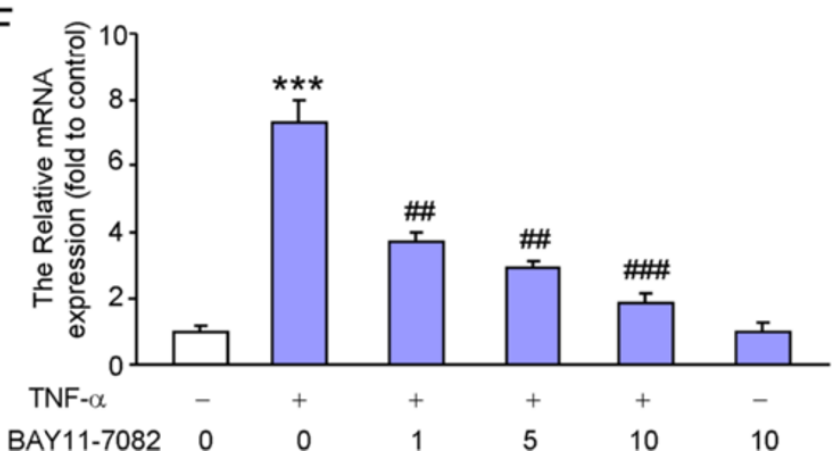

Figure 5 TNF-a induces NFKB-dependent CXCL1 increase in cultured astrocytes. (A-D) CXCL1 was expressed in control astrocytes (A) and increased at $1 \mathrm{~h}$ after TNF-a incubation (B). Double staining of CXCL1 (B) with GFAP (C) shows the expression of CXCL1 by astrocytes (D). (E) ELISA results show TNF-a-induced CXCL1 upregulation was decreased by pretreatment with NFkB inhibitor, BAY11-7082. ${ }^{* *} P<0.001$ vs. control. $\# P<0.05$, \#\#\# <0.001 vs. TNF-a treatment. (F) Quantitative PCR shows TNF-a-induced CXCL1 mRNA increase was decreased by BAY11-7082. ${ }_{* * * P}<0.001$ vs. control. \#\#P<0.01, \#\#\#P<0.001 vs. TNF-a treatment.
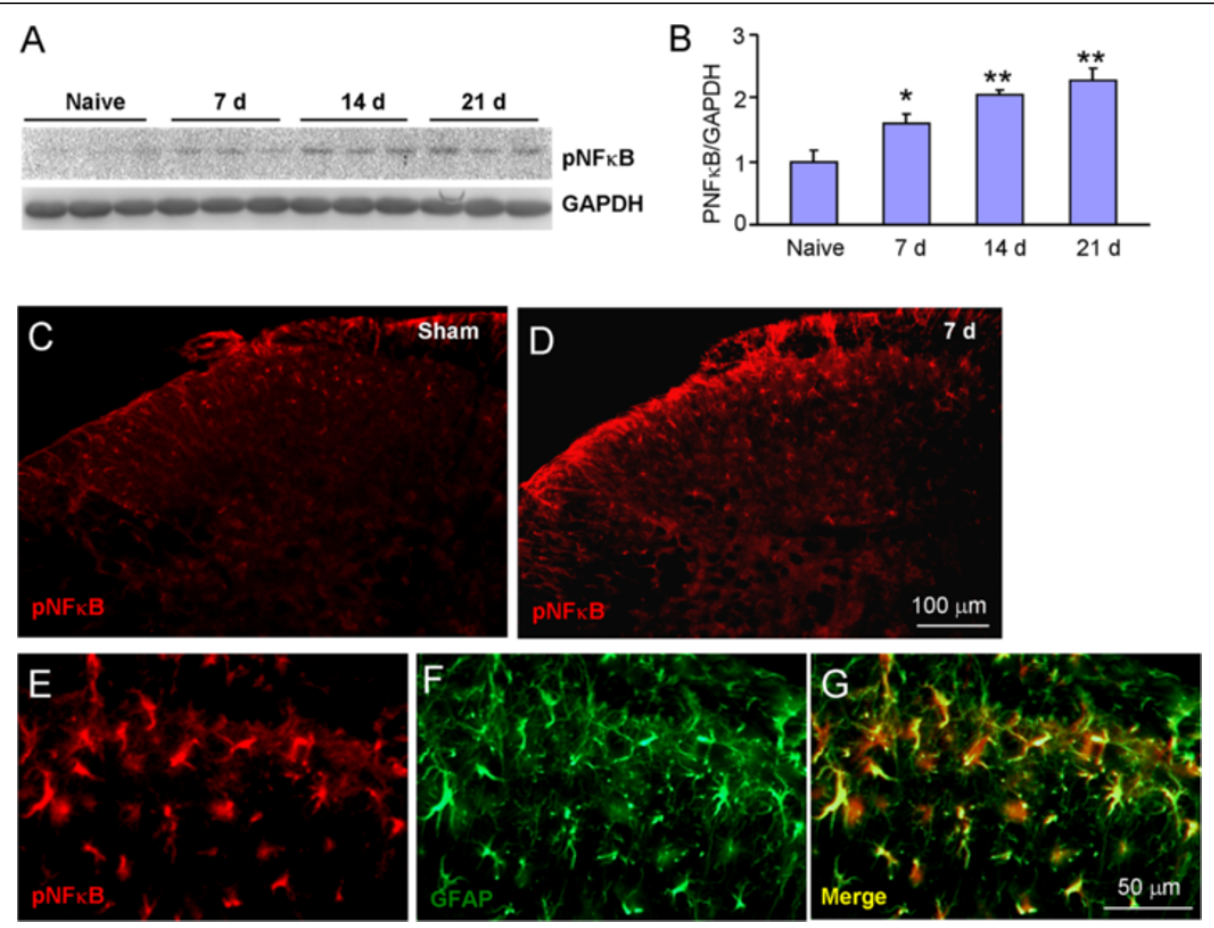

Figure 6 RM-1 cell inoculation increases pNFKB expression in spinal astrocytes. (A,B) Western blot shows that tumor cell inoculation increased pNFKB expression in the spinal cord at 7 days, 14 days, and 21 days. ${ }^{*} P<0.05$, ${ }^{*} P<0.01$ vs. naive. One-way ANOVA followed by Newman-Keuls test. $\mathrm{n}=4$ mice per group. (C, D) Immunostaining shows that pNFkB was expressed in the superficial dorsal horn in sham animals (C), increased at 7 days in inoculated animals (D). (E-G) Double staining showed pNFKB was colocalized with GFAP. 

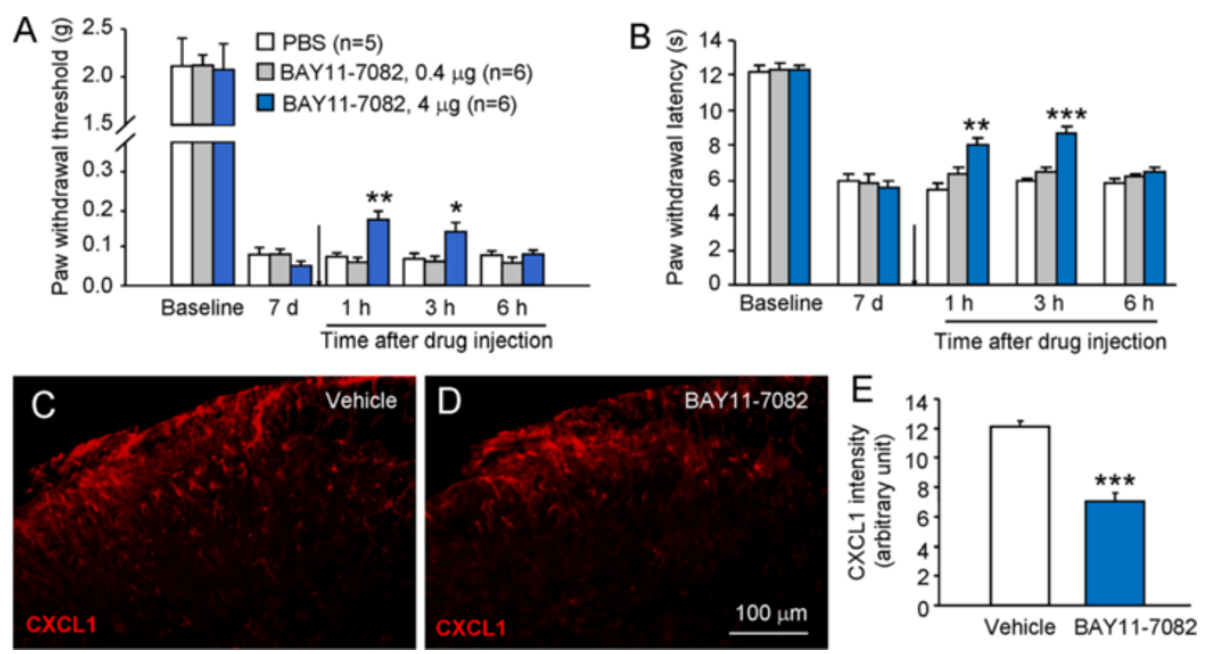

Figure 7 NFKB inhibitor attenuated RM-1 cell inoculation-induced pain hypersensitivity and upregulation of CXCL1 in the spinal cord.

(A, B) Intrathecal injection of NFKB inhibitor, BAY11-7082 at the dose of $0.4 \mu \mathrm{g}$ had no effect on mechanical allodynia or heat hyperalgesia, whereas at the dose of $4 \mu \mathrm{g}$ attenuated mechanical allodynia (A) and heat hyperalgesia (B) at $1 \mathrm{~h}$ and $3 \mathrm{~h}$. ${ }^{*} P<0.05,{ }^{* *} P<0.01,{ }^{* * *} P<0.001$ vs. vehicle. One-way ANOVA followed by Newman-Keuls test. (C, D) Immunostaining of CXCL1 in the spinal cord in vehicle and BAY11-7082-treated animals. (E) The CXCL1-IF intensity was decreased by BAY11-7082. ${ }^{* * *} P<0.001$ vs. vehicle. $\mathrm{n}=4$ mice per group.

Contusion injury of spinal cord induces rapid but transient (6 h) CXCL1 mRNA in the spinal cord [29]. Spinal nerve ligation induces persistent CXCL1 mRNA and protein increase, which was peaked at 10 days, declined at 21 days [16]. In this study, CXCL1 mRNA and protein was progressively increased in 21 days after tumor cell inoculation, indicating CXCL1 play distinct roles in different pain conditions.

Accumulating evidence supports that glial cells (astrocytes and microglia) are activated in the spinal cord after tumor cells inoculation in the skin or bone marrow [30-35]. Consistent with these studies, we found that the expression of astrocytic marker, GFAP was increased from 7 days to 21 days in the spinal cord. Spinal microglia was also activated for more than 21 days in this model (unpublished observation). In addition, the glial activation was correlated with the pain behavior. It has been shown that intrathecal injection of glial function inhibitor, fluorocitrate or microglia inhibitor, minocycline attenuated allodynia induced by Walker 256 inoculation [33,36,37], supporting the view that spinal astrocytes and microglia are involved in the pathogenesis of BCP.

It is increasingly recognized that astrocytes mediate neuroinflammation by the release of gliotransmitters such as proinflammatory cytokines (for example, IL-1 $\beta$ ) $[30,38]$ and chemokines (for example, CCL2 and CCL7) $[23,39]$. Our present study showed that CXCL1 was produced by spinal astrocytes after tumor cells inoculation. In agreement with present results, CXCL1 mRNA is found to be upregulated in spinal astrocytes after spinal cord injury in rats [40] or spinal nerve ligation in mice
[16]. CXCL1 is induced in brain astrocytes by neuronal injury and intracerebroventricular administration of endothelin-1 [41,42]. CXCL1 is also selectively expressed in hypertropic astrocytes after active multiple sclerosis lesions in humans $[43,44]$. These data suggest that CXCL1 is one of astrogliotransmitters that regulate neuroinflammation.

Several chemokines, such as CCL2, CX3CL1, CCL5, or CXCL10 are recently found to be involved in BCP $[10,11,45,46]$. In our study, intrathecal injection of CXCL1 neutralizing antibody at 7 days after inoculation attenuated tumor cell inoculation-induced mechanical allodynia and heat hyperalgesia. This antibody also attenuated spinal nerve ligation-induced neuropathic pain at 10 days, but not at 1 day after ligation [16], indicating the major role of CXCL1 in the maintenance of chronic pain.

\section{NFKB mediates CXCL1 upregulation and contributes to bone cancer pain}

The proinflammatory cytokine TNF- $\alpha$ is an essential trigger for the development of neuropathic pain [16,47]. TNF- $\alpha$ mRNA is rapidly ( $1 \mathrm{~d}$ ) and dramatically (fivefold) increased in the spinal cord after spinal nerve ligation [16]. TNF- $\alpha$ protein is upregulated in the spinal cord at 3 days after tumor cell inoculation [48]. In addition, combined deletion of TNF receptor (TNFR) 1 and TNFR2 inhibits fibrosarcoma inoculation-induced astrogliosis in the spinal cord and mechanical allodynia [35]. These data indicate that TNF- $\alpha$ can be rapidly increased in the spinal cord and acts on astrocytes to initiate astrocytes activation and BCP. In cultured astrocytes, 


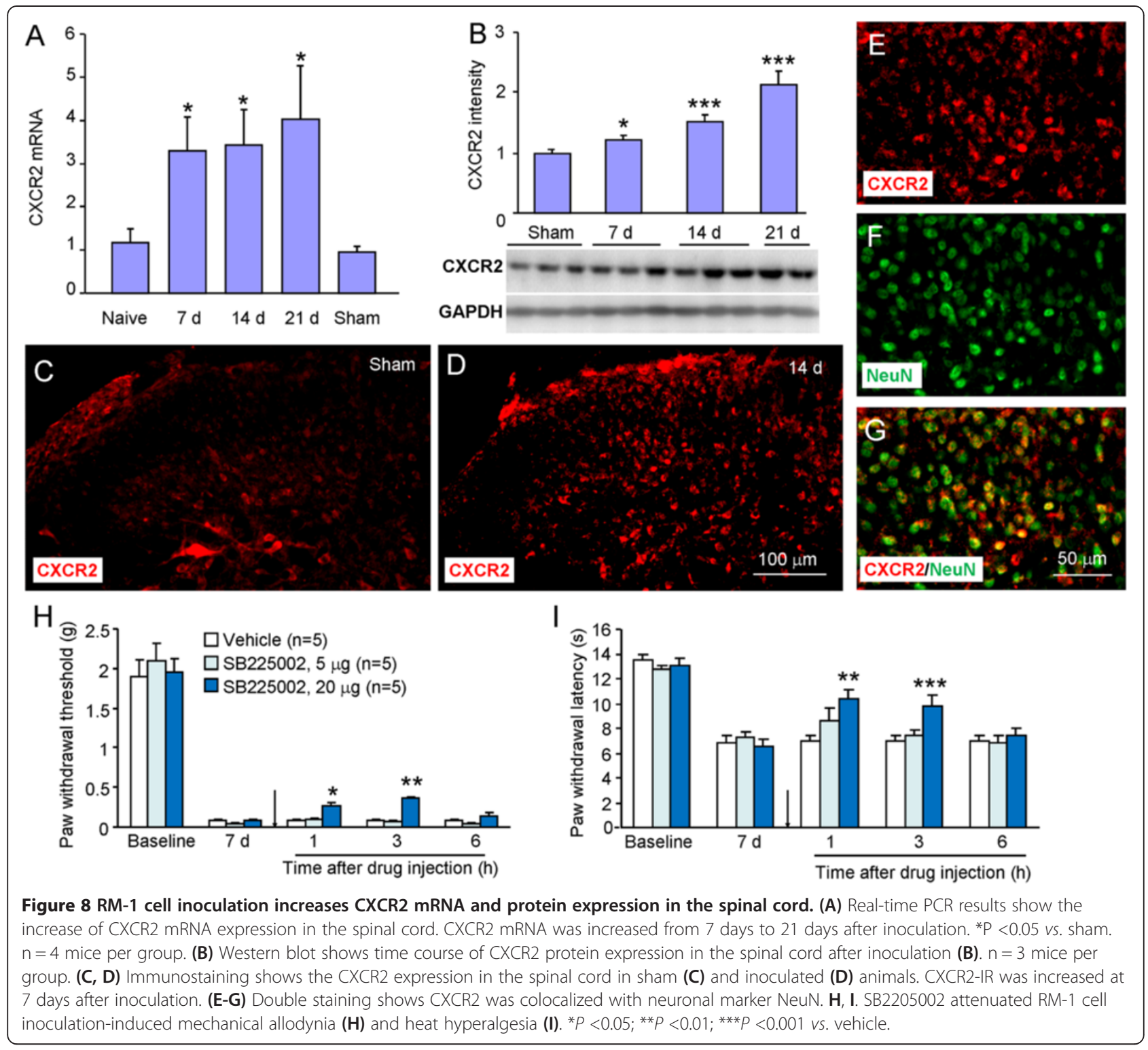

TNF- $\alpha$ induces rapid and dramatic CXCL1 upregulation [16]. Intrathecal injection TNF- $\alpha$ not only increases CXCL1 expression in spinal astrocytes but also induces heat hyperalgesia [16]. These data suggest that the activation of $\mathrm{NFkB} / \mathrm{CXCL1}$ signaling after tumor cell inoculation may also be triggered by TNF- $\alpha$ increase.

$N_{K} \mathrm{~B}$ regulates the transcription of many inflammatory mediators, including those for chemokines, proinflammatory cytokines, and adhesion molecules [20,26]. $\mathrm{NF} \kappa \mathrm{B}$ is found to regulate CXCL1 transcription in Hs294T malignant melanoma cells [17]. Here, NFkB mediated CXCL1 production in cultured astrocytes and spinal astrocytes. In addition, inoculation persistently increased $\mathrm{NFKB}_{\mathrm{B}}$ activation in the spinal cord. Evidence suggests that the activation of $\mathrm{NF}_{\mathrm{K} B}$ following tissue injury or nerve damage is related to the development and maintenance of neuropathic pain. For example, inhibition of NFKB activation in the spinal level by specific inhibitors or lentivirus partly prevents the development of neuropathic pain $[20,26]$. NFאB inhibitor also attenuates established neuropathic pain $[20,49]$. Our results showed that intrathecal $\mathrm{NF}_{\kappa} \mathrm{B}$ inhibitor at 7 days after inoculation attenuated tumoral hypersensitivity and decreased CXCL1 level, supporting the role of NFKB in the maintenance of $\mathrm{BCP}$ via CXCL1 production in the spinal cord.

Our data further showed that NFKB was predominantly expressed in astrocytes of the spinal cord. Consistently, $\mathrm{pNF} \mathrm{B}$ expression in astrocytes was found in the spinal cord following spinal nerve injury [24] and in the medullary dorsal horn following the inferior alveolar nerve injury [49]. However, activated NFKB is also found 
in macrophages/microglia in the spinal cord after spinal cord injury [50] or spinal nerve injury in rats [51]. The discrepency of the cellular distribution of NFKB in the spinal cord may be due to different animal species or different antibodies, which need to be further clarified in the future.

\section{CXCL1/CXCR2 signaling mediates astroglial-neuronal interaction in bone cancer pain}

Chemokines act through a family of seven transmembrane $\mathrm{G}$ protein-coupled receptors to exert their biological effects. CXCR2 is the major receptor of CXCL1 $[52,53]$. The CXCR2 receptor has been detected on neurons [54,55], oligodendrocyte progenitors [44,56], and microglia $[57,58]$ in brain. In DRG, CXCR2 are expressed in neurons and CXCL1 increases the sodium currents, potassium currents in small diameter rat sensory neurons $[13,14]$. In this study, tumor cell inoculation increased CXCR2 expression in spinal neurons. Inhibition of CXCR2 by its selective antagonist attenuated tumoral hypersensitivity, suggesting the involvement of neuronal CXCR2 in BCP.

Glial-neuronal interaction has been implicated to contribute to central sensitization under pathological conditions [5]. Here the respective expression of CXCL1 and CXCR2 in astrocytes and neurons suggest they may be involved in astroglial-neuronal interaction. Our recent data showed that intrathecal injection of CXCL1 induced rapid, CXCR2-dependent ERK and CREB activation mainly in spinal cord neurons. It is known that the activated ERK can be translocated into nucleus, activates transcription factors including CREB, and further regulates gene transcription (for example, c-Fos and COX-2) to maintain central sensitization and chronic pain [59]. Therefore, CXCL1 may regulate BCP through upregulation of pain-related proteins. In addition, we observed that CXCL1 increases NMDA-induced currents on Lamina II neurons of the spinal cord (unpublished observation), suggesting CXCL1 may also be involved in the maintenance of central sensitization through direct regulation of neuronal excitability.

\section{Conclusions}

In this study, we found that inoculation of RM-1 cells into mouse femur induced bone destruction and pain hypersensitivity. In association with these changes, chemokine CXCL1 and its receptor CXCR2 were, respectively, increased in spinal astrocytes and neurons. Moreover, $\mathrm{NF \kappa B}$ was involved in the production of CXCL1 in spinal astrocytes. Our data suggest that CXCL1/CXCR2-mediated astroglial-neuronal interaction contributes to the maintenance of tumoral hypersensitivity. CXCL1 signaling may serve as a novel target for the treatment of metastatic prostate cancer-induced BCP.

\section{Abbreviations}

BCP: Bone cancer pain; CXCL1: Chemokine CXC motif ligand 1; CXCR2: Chemokine CXC motif receptor 2; GAPDH: Glyceraldehyde-3phophate dehydrogenase; GFAP: Glial fibrillary acidic protein; NFkB: Nuclear factor kappa B; PWL: Paw withdrawal latency; PWT: Paw withdrawal threshold; TNF-a: Tumor necrosis factor-a.

\section{Competing interests}

The authors declare no competing interests.

\section{Authors' contributions}

JX carried out the animal surgery, behavioral testing, cell culture, immunohistochemistry, and western blot experiments. MDZ and XZ participated in the animal surgery and behavioral testing. HT did the X-ray scan. $\mathrm{JHZ}$ and XBW participated to the design of the experiments. YJG conceived of the project, coordinated and supervised the experiments, analyzed data, and wrote the manuscript. All authors read and approved the final manuscript.

\section{Acknowledgements}

This study was supported by the National Natural Science Foundation of China (31171062, 31371121, and 81300954), Science and Technology Project in Nantong (HS12926), Innovation Fund for Graduate Students in Nantong University (YKC12040), and the Priority Academic Program Development of Jiangsu Higher Education Institutions.

\section{Author details}

'Pain Research Laboratory, Institute of Nautical Medicine, Jiangsu Key Laboratory of Neuroregeneration, Nantong University, 19 Qixiu Road, Nantong 226001, China. ${ }^{2}$ Department of Orthopedics, Affiliated Hospital to Nantong University, Nantong 226001, China. ${ }^{3}$ Department of Radiology, Affiliated Hospital to Nantong University, Nantong 226001, China.

${ }^{4}$ Department of Urology, Haimen People's Hospital, Haimen, Jiangsu Province 226100, China.

Received: 23 January 2014 Accepted: 21 February 2014

Published: 1 March 2014

\section{References}

1. Coleman RE: Clinical features of metastatic bone disease and risk of skeletal morbidity. Clin Cancer Res 2006, 12:6243s-6249s.

2. Mantyh P: Bone cancer pain: causes, consequences, and therapeutic opportunities. Pain 2013, Suppl 1:S54-S62.

3. White FA, Jung $H$, Miller RJ: Chemokines and the pathophysiology of neuropathic pain. Proc Natl Acad Sci U S A 2007, 104:20151-20158.

4. Kiguchi N, Kobayashi Y, Kishioka S: Chemokines and cytokines in neuroinflammation leading to neuropathic pain. Curr Opin Pharmacol 2012, 12:55-61.

5. Gao YJ, Ji RR: Chemokines, neuronal-glial interactions, and central processing of neuropathic pain. Pharmacol Ther 2010, 126:56-68.

6. Gao YJ, Ji RR: Targeting astrocyte signaling for chronic pain. Neurotherapeutics 2010, 7:482-493.

7. Ji RR, Berta T, Nedergaard M: Glia and pain: is chronic pain a gliopathy? Pain 2013, Suppl 1:S10-S28.

8. Scholz J, Woolf $\mathrm{CJ}$ : The neuropathic pain triad: neurons, immune cells and glia. Nat Neurosci 2007, 10:1361-1368.

9. Pevida M, Gonzalez-Rodriguez S, Lastra A, Garcia-Suarez O, Hidalgo A, Menendez L, Baamonde A: Involvement of spinal chemokine CCL2 in the hyperalgesia evoked by bone cancer in mice: a role for astroglia and microglia. Cell Mol Neurobiol 2013. Epub ahead of print.

10. $\mathrm{Hu} J \mathrm{H}$, Zheng $X Y$, Yang JP, Wang LN, Ji FH: Involvement of spinal monocyte chemoattractant protein-1 (MCP-1) in cancer-induced bone pain in rats. Neurosci Lett 2012, 517:60-63.

11. Bu H, Shu B, Gao F, Liu C, Guan X, Ke C, Cao F, Hinton AO Jr, Xiang H, Yang $H$, Tian X, Tian Y: Spinal IFN-gamma-induced protein-10 (CXCL10) mediates metastatic breast cancer-induced bone pain by activation of microglia in rat models. Breast Cancer Res Treat 2014, 143:255-263.

12. Yang J, Richmond A: Constitutive IkappaB kinase activity correlates with nuclear factor-kappaB activation in human melanoma cells. Cancer Res 2001, 61:4901-4909.

13. Wang JG, Strong JA, Xie W, Yang RH, Coyle DE, Wick DM, Dorsey ED, Zhang JM: The chemokine CXCL1/growth related oncogene increases sodium 
currents and neuronal excitability in small diameter sensory neurons. Mol Pain 2008, 4:38.

14. Yang RH, Strong JA, Zhang JM: NF-kappaB mediated enhancement of potassium currents by the chemokine CXCL1/growth related oncogene in small diameter rat sensory neurons. Mol Pain 2009, 5:26.

15. Dong F, Du YR, Xie W, Strong JA, He XJ, Zhang JM: Increased function of the TRPV1 channel in small sensory neurons after local inflammation or in vitro exposure to the pro-inflammatory cytokine GRO/KC. Neurosci Bull 2012, 28:155-164.

16. Zhang ZJ, Cao DL, Zhang X, Ji RR, Gao YJ: Chemokine contribution to neuropathic pain: Respective induction of CXCL1 and CXCR2 in spinal cord astrocytes and neurons. Pain 2013, 154:2185-2197.

17. Devalaraja MN, Wang DZ, Ballard DW, Richmond A: Elevated constitutive IkappaB kinase activity and IkappaB-alpha phosphorylation in Hs294T melanoma cells lead to increased basal MGSA/GRO-alpha transcription. Cancer Res 1999, 59:1372-1377.

18. de Mos M, Laferriere A, Millecamps M, Pilkington M, Sturkenboom MC, Huygen FJ, Coderre TJ: Role of NFkappaB in an animal model of complex regional pain syndrome-type I (CRPS-I). J Pain 2009, 10:1161-1169.

19. O'Rielly DD, Loomis CW: Spinal nerve ligation-induced activation of nuclear factor kappaB is facilitated by prostaglandins in the affected spinal cord and is a critical step in the development of mechanical allodynia. Neuroscience 2008, 155:902-913.

20. Ledeboer A, Gamanos M, Lai W, Martin D, Maier SF, Watkins LR, Quan N: Involvement of spinal cord nuclear factor kappaB activation in rat models of proinflammatory cytokine-mediated pain facilitation. Eur J Neurosci 1977-1986, 2005:22.

21. Hylden $J$, Wilcox $G L$ : Intrathecal morphine in mice: a new technique. Eur J Pharmacol 1980, 67:313-316.

22. Chaplan SR, Bach FW, Pogrel JW, Chung JM, Yaksh TL: Quantitative assessment of tactile allodynia in the rat paw. J Neurosci Methods 1994, 53:55-63.

23. Gao YJ, Zhang L, Samad OA, Suter MR, Yasuhiko K, Xu ZZ, Park JY, Lind AL, Ma Q, Ji RR: JNK-induced MCP-1 production in spinal cord astrocytes contributes to central sensitization and neuropathic pain. J Neurosci 2009, 29:4096-4108.

24. Miyoshi K, Obata K, Kondo T, Okamura H, Noguchi K: Interleukin-18mediated microglia/astrocyte interaction in the spinal cord enhances neuropathic pain processing after nerve injury. J Neurosci 2008, 28:12775-12787.

25. Zhuang ZY, Wen YR, Zhang DR, Borsello T, Bonny C, Strichartz GR, Decosterd I, Ji RR: A peptide c-Jun N-terminal kinase (JNK) inhibitor blocks mechanical allodynia after spinal nerve ligation: respective roles of JNK activation in primary sensory neurons and spinal astrocytes for neuropathic pain development and maintenance. J Neurosci 2006, 26:3551-3560

26. Meunier A, Latremoliere A, Dominguez E, Mauborgne A, Philippe S, Hamon M, Mallet J, Benoliel JJ, Pohl M: Lentiviral-mediated targeted NF-kappaB blockade in dorsal spinal cord glia attenuates sciatic nerve injuryinduced neuropathic pain in the rat. Mol Ther 2007, 15:687-697.

27. Currie GL, Delaney A, Bennett MI, Dickenson AH, Egan K, Vesterinen HM Sena ES, Macleod MR, Colvin LA, Fallon MT: Animal models of bone cancer pain: systematic review and meta-analyses. Pain 2013, 154:917-926.

28. Sabino MA, Luger NM, Mach DB, Rogers SD, Schwei MJ, Mantyh PW: Different tumors in bone each give rise to a distinct pattern of skeletal destruction, bone cancer-related pain behaviors and neurochemical changes in the central nervous system. Int J Cancer 2003, 104:550-558.

29. McTique DM, Tani M, Krivacic K, Chernosky A, Kelner GS, Maciejewski D, Maki R, Ransohoff RM, Stokes BT: Selective chemokine mRNA accumulation in the rat spinal cord after contusion injury. $J$ Neurosci Res 1998, 53:368-376.

30. Zhang RX, Liu B, Wang L, Ren K, Qiao JT, Berman BM, Lao L: Spinal glial activation in a new rat model of bone cancer pain produced by prostate cancer cell inoculation of the tibia. Pain 2005, 118:125-136.

31. Hald A, Nedergaard S, Hansen RR, Ding M, Heegaard AM: Differential activation of spinal cord glial cells in murine models of neuropathic and cancer pain. Eur J Pain 2009, 13:138-145.

32. Gao YJ, Cheng JK, Zeng Q, Xu ZZ, Decosterd I, Xu X, Ji RR: Selective inhibition of JNK with a peptide inhibitor attenuates pain hypersensitivity and tumor growth in a mouse skin cancer pain model. Exp Neurol 2009, 219:146-155.
33. Mao-Ying QL, Wang XW, Yang CJ, Li X, Mi WL, Wu GC, Wang YQ: Robust spinal neuroinflammation mediates mechanical allodynia in Walker 256 induced bone cancer rats. Mol Brain 2012, 5:16.

34. Ren BX, Gu XP, Zheng YG, Liu CL, Wang D, Sun YE, Ma ZL: Intrathecal injection of metabotropic glutamate receptor subtype 3 and 5 agonist/ antagonist attenuates bone cancer pain by inhibition of spinal astrocyte activation in a mouse model. Anesthesiology 2012, 116:122-132.

35. Geis C, Graulich M, Wissmann A, Hagenacker T, Thomale J, Sommer C, Schafers M: Evoked pain behavior and spinal glia activation is dependent on tumor necrosis factor receptor 1 and 2 in a mouse model of bone cancer pain. Neuroscience 2010, 169:463-474.

36. Wang LN, Yao M, Yang JP, Peng J, Peng Y, Li CF, Zhang YB, Ji FH, Cheng $H_{\text {, }}$ Xu QN, Wang XY, Zuo JL: Cancer-induced bone pain sequentially activates the ERK/MAPK pathway in different cell types in the rat spinal cord. Mol Pain 2011, 7:48

37. Wang LN, Yang JP, Zhan Y, Ji FH, Wang XY, Zuo JL, Xu QN: Minocycline-induced reduction of brain-derived neurotrophic factor expression in relation to cancer-induced bone pain in rats. J Neurosci Res 2012, 90:672-681.

38. Weyerbacher AR, Xu Q, Tamasdan C, Shin SJ, Inturrisi CE: N-Methyl-Daspartate receptor (NMDAR) independent maintenance of inflammatory pain. Pain 2010, 148:237-246.

39. Imai S, Ikegami D, Yamashita A, Shimizu T, Narita M, Niikura K, Furuya M, Kobayashi Y, Miyashita K, Okutsu D, Kato A, Nakamura A, Araki A, Omi K, Nakamura M, James Okano H, Okano H, Ando T, Takeshima H, Ushijima T, Kuzumaki N, Suzuki T, Narita M: Epigenetic transcriptional activation of monocyte chemotactic protein 3 contributes to long-lasting neuropathic pain. Brain 2013, 136:828-843.

40. Pineau I, Sun L, Bastien D, Lacroix S: Astrocytes initiate inflammation in the injured mouse spinal cord by promoting the entry of neutrophils and inflammatory monocytes in an IL-1 receptor/MyD88-dependent fashion. Brain Behav Immunol 2010, 24:540-553.

41. Katayama T, Tanaka H, Yoshida T, Uehara T, Minami M: Neuronal injury induces cytokine-induced neutrophil chemoattractant-1 (CINC-1) production in astrocytes. J Pharmacol Sci 2009, 109:88-93.

42. Koyama Y, Baba A, Matsuda T: Production of monocyte chemoattractant protein-1 and cytokine-induced neutrophil chemoattractant-1 in rat brain is stimulated by intracerebroventricular administration of an endothelin ETB receptor agonist. Neuroreport 2007, 18:1275-1279.

43. Omari KM, John G, Lango R, Raine CS: Role for CXCR2 and CXCL1 on glia in multiple sclerosis. Glia 2006, 53:24-31.

44. Omari KM, John GR, Sealfon SC, Raine CS: CXC chemokine receptors on human oligodendrocytes: implications for multiple sclerosis. Brain 2005, 128:1003-1015.

45. Hu JH, Yang JP, Liu L, Li CF, Wang LN, Ji FH, Cheng H: Involvement of CX3CR1 in bone cancer pain through the activation of microglia p38 MAPK pathway in the spinal cord. Brain Res 2012, 1465:1-9.

46. Pevida M, Lastra A, Meana A, Hidalgo A, Baamonde A, Menendez L: The chemokine CCL5 induces CCR1-mediated hyperalgesia in mice inoculated with NCTC 2472 tumoral cells. Neuroscience 2014, 259:113-125.

47. $X u$ JT, Xin WJ, Zang Y, Wu CY, Liu XG: The role of tumor necrosis factoralpha in the neuropathic pain induced by Lumbar 5 ventral root transection in rat. Pain 2006, 123:306-321.

48. Liu S, Liu YP, Song WB, Song XJ: EphrinB-EphB receptor signaling contributes to bone cancer pain via Toll-like receptor and proinflammatory cytokines in rat spinal cord. Pain 2013, 154:2823-2835.

49. Lee MK, Han SR, Park MK, Kim MJ, Bae YC, Kim SK, Park JS, Ahn DK: Behavioral evidence for the differential regulation of p-p38 MAPK and pNF-kappaB in rats with trigeminal neuropathic pain. Mol Pain 2011, 7:57.

50. Bethea JR, Castro M, Keane RW, Lee TT, Dietrich WD, Yezierski RP: Traumatic spinal cord injury induces nuclear factor-kappaB activation. J Neurosci 1998, 18:3251-3260.

51. Suter MR, Wen YR, Decosterd I, Ji RR: Do glial cells control pain? Neuron Glia Biol 2007, 3:255-268.

52. Cartier L, Hartley O, Dubois-Dauphin M, Krause KH: Chemokine receptors in the central nervous system: role in brain inflammation and neurodegenerative diseases. Brain Res Brain Res Rev 2005, 48:16-42.

53. Savarin-Vuaillat C, Ransohoff RM: Chemokines and chemokine receptors in neurological disease: raise, retain, or reduce? Neurotherapeutics 2007, 4:590-601.

54. Horuk R, Martin AW, Wang Z, Schweitzer L, Gerassimides A, Guo H, Lu Z, Hesselgesser J, Perez HD, Kim J, Parker J, Hadley TJ, Peiper SC: Expression of 
chemokine receptors by subsets of neurons in the central nervous system. J Immunol 1997, 158:2882-2890.

55. Valles A, Grijpink-Ongering L, de Bree FM, Tuinstra T, Ronken E: Differential regulation of the CXCR2 chemokine network in rat brain trauma: implications for neuroimmune interactions and neuronal survival. Neurobiol Dis 2006, 22:312-322.

56. Nguyen D, Stangel M: Expression of the chemokine receptors CXCR1 and CXCR2 in rat oligodendroglial cells. Brain Res Dev Brain Res 2001،

128:77-81.

57. Popivanova BK, Koike K, Tonchev AB, Ishida Y, Kondo T, Ogawa S, Mukaida $\mathrm{N}$, Inoue $\mathrm{M}$, Yamashima T: Accumulation of microglial cells expressing ELR motif-positive CXC chemokines and their receptor CXCR2 in monkey hippocampus after ischemia-reperfusion. Brain Res 2003, 970:195-204.

58. Filipovic R, Jakovcevski I, Zecevic N: GRO-alpha and CXCR2 in the human fetal brain and multiple sclerosis lesions. Dev Neurosci 2003, 25:279-290.

59. Ji RR, Strichartz G: Cell signaling and the genesis of neuropathic pain. SCi STKE 2004, 2004:reE14.

doi:10.1186/1742-2094-11-38

Cite this article as: Xu et al: NFKB-mediated CXCL1 production in spinal cord astrocytes contributes to the maintenance of bone cancer pain in mice. Journal of Neuroinflammation 2014 11:38.

\section{Submit your next manuscript to BioMed Central and take full advantage of:}

- Convenient online submission

- Thorough peer review

- No space constraints or color figure charges

- Immediate publication on acceptance

- Inclusion in PubMed, CAS, Scopus and Google Scholar

- Research which is freely available for redistribution

Submit your manuscript at www.biomedcentral.com/submit
C Biomed Central 